\title{
A Woman with Extreme Fatigue
}

Christopher D iM aio M D, Chief M edical Resident, Internal M edicine

A 23 year old female presented to her primary care provider's office complaining of extreme fatigue over the past few weeks.

The patient's past medical history is significant for stage 2B H odgkin's lymphoma, diagnosed 2 years ago. The patient received 4 cycles of chemotherapy with ABVD, as well as multiple rounds of radiation therapy. U pon completion of treatment, her H odgkin's was considered cured. The patient did develop hypothyroidism secondary to the radiation treatments, and requires permanent thyroid hormone replacement.

Four weeks prior to presentation, the patient noted the onset of her symptoms. She stated that she has been taking a lot of naps throughout the day, which is unusual for her. She denied fevers, chills, night sweats, changes in weight, or viral illnesses over this time.

At her primary care physician's office, the patient was found to have elevated LFT 's. (Table 1)

Table 1. Outpatient Laboratory Values

\begin{tabular}{l|l|l}
\hline & $\begin{array}{l}4 \text { weeks prior } \\
\text { to admission }\end{array}$ & $\begin{array}{l}1 \text { week prior } \\
\text { to admission }\end{array}$ \\
\hline Total protein & 6.2 & - \\
\hline Albumin & 3.2 & 2.9 \\
\hline Total bilirubin & 1.2 & 2.6 \\
\hline Direct bilirubin & - & - \\
\hline AST & 149 & 152 \\
\hline ALT & - & 198 \\
\hline Alkaline phosphatase & 182 & 158 \\
\hline
\end{tabular}

The patient was referred to a gastroenterologist for evaluation and work-up. She began to develop visible jaundice, generalized pruritus, and dark urine, without fevers, abdominal pain, nausea, vomiting, or pale stools. She was subsequently hospitalized for further work-up.

O n review of systems, the patient denies chest pain, shortness of breath, lymphadenopathy, diarrhea, constipation, myalgias, joint pains, or changes in her menstrual cycle. $\mathrm{H}$ er medications include levothyroxine and D epo-provera injections for birth control. She has used tobacco for the past 8 years, less than one-half pack of cigarettes per day, and consumes about 5 beers over 1 weekend per month. She denies any IVDA or recreational drug use. The patient has one tattoo, dating about 8 years. She is sexually active in a monogamous relationship and her partner uses condoms.

H er vitals on presentation follow: blood pressure 126/78 $\mathrm{mm} \mathrm{H} \mathrm{g}$, heart rate 82 , respirations 16 , and temperature 98.6. The patient appears her stated age, and is in no apparent distress. Sclerae are anicteric, and conjunctivae pink. No oropharyngeal exudates or apthous ulcers are seen, and there is no evidence of cervical, axillary, supraclavicular, or inguinal lymphadenopathy. Thyroid is not enlarged or tender. Cardiac exam is normal and her lungs are clear. Her abdomen is mildly obese, nontender and nondistended, with normoactive bowel sounds. There is no hepatosplenomegaly. No peripheral edema or joint abnormalities are appreciated, and she is neurologically intact.

D ermatologic exam is notable for generalized jaundice.

Admission laboratory data is listed in Table 2.

Table 2. Laboratory Values Upon Admission

\begin{tabular}{|c|c|c|c|}
\hline $\mathrm{Na}$ & 140 & Hep B surface & \\
\hline $\mathrm{K}$ & 3.5 & & Negative \\
\hline $\mathrm{Cl}$ & 109 & Hep B core & \\
\hline $\mathrm{CO} 2$ & 27 & antibody & Negative \\
\hline BUN & 10 & Hep B surface & \\
\hline $\mathrm{Cr}$ & .9 & antibody & Negative \\
\hline Wbc & 5.0 & $\begin{array}{l}\text { Hep C } \\
\text { antibody }\end{array}$ & Negative \\
\hline $\mathrm{Hgb}$ & $9.4^{*}$ & $\mathrm{AMA}$ & Negative \\
\hline $\mathrm{MCV}$ & 109 & ANA & Negative \\
\hline Plts & 124 & Ceruloplasmin & 6.0 \\
\hline Total protein & 5.6 & Iron & 122 \\
\hline Albumin & 2.5 & TIBC & 127 \\
\hline Total bilirubin & 10.9 & Iron saturation & $96 \%$ \\
\hline Direct bilirubin & 4.3 & Ferritin & 1030 \\
\hline AST & 95 & Reticulocytes & 15.1 \\
\hline ALT & 30 & Absolute & \\
\hline Alkaline & & reticulocyte count & 110.9 \\
\hline phosphatase & 33 & $\mathrm{LDH}$ & 189 \\
\hline PT & 21.0 & $\mathrm{~B} 12$ & 1242 \\
\hline INR & 1.82 & Folate & 13.4 \\
\hline PTT & 43 & Haptoglobin & $<6.0$ \\
\hline Hep A lgM/lgG & Negative & $\mathrm{TSH}$ & 3.69 \\
\hline
\end{tabular}

*Hgb was 14.4 approximately 1 year ago. 